\title{
Induction of Metastasis by Low-dose Gemcitabine in a Pancreatic Cancer Orthotopic Mouse Model: An Opposite Effect of Chemotherapy
}

\author{
NORIHIKO SUGISAWA ${ }^{1,2,3}$, KENTARO MIYAKE ${ }^{1,2}$, TAKASHI HIGUCHI ${ }^{1,2}$, HIROMICHI OSHIRO $^{1,2}$, \\ ZHIYING ZHANG ${ }^{1,2}$, JUN HO PARK $^{1,2}$, KEI KAWAGUCHI $^{3}$, SANT P. CHAWLA $^{4}$, \\ MICHAEL BOUVET $^{2}$, SHREE RAM SINGH ${ }^{5}$, MICHIAKI UNNO ${ }^{3}$ and ROBERT M. HOFFMAN ${ }^{1,2}$ \\ ${ }^{1}$ AntiCancer, Inc., San Diego, CA, U.S.A.; \\ ${ }^{2}$ Department of Surgery, University of California, San Diego, CA, U.S.A.; \\ ${ }^{3}$ Department of Surgery, Tohoku University Graduate School of Medicine, Sendai, Japan; \\ ${ }^{4}$ Sarcoma Oncology Center, Santa Monica, CA, U.S.A.; \\ ${ }^{5}$ Basic Research Laboratory, National Cancer Institute, Frederick, MD, U.S.A.
}

\begin{abstract}
Background/Aim: Gemcitabine is standard first-line treatment for patients with advanced pancreatic cancer, however the efficacy is limited. Although acquired drug resistance and side-effects are known to limit efficacy, opposite effects of a drug, which enhance the malignancy of treated cancer, have been observed but are not well understood. The aim of the present study was to determine whether gemcitabine has such opposite effects on the BxPC-3 human pancreatic cancer cell line expressing green fluorescent protein (BxPC-3$G F P)$ in an orthotopic mouse model. Materials and Methods: BxPC-3-GFP tumors grown subcutaneously in nude mice were harvested. Tumor fragments were orthotopically implanted in the tail of the pancreas of nude mice using the technique of surgical orthotopic implantation. The BxPC-3-GFP orthotopic models were divided randomly into three groups: Group 1: untreated control; Group 2: low-dose gemcitabine (weekly intraperitoneal injection at $25 \mathrm{mg} / \mathrm{kg}$ for 6 weeks); Group 3: high-dose gemcitabine (weekly intraperitoneal injection at 125
\end{abstract}

This article is freely accessible online.

Correspondence to: Robert M. Hoffman, AntiCancer, Inc., 7917 Ostrow St., San Diego, CA 92111, U.S.A. Tel: +1 8586542555, Fax: +1 8582684175, e-mail: all@anticancer.com; Shree Ram Singh, Basic Research Laboratory, National Cancer Institute, Frederick, MD 217021201, U.S.A. Tel: +1 3018467331, e-mail: singhshr@mail.nih.gov; Michiaki Unno, Department of Surgery, Tohoku University Graduate School of Medicine, 1-1, Seiryo-machi, Aoba-ku, Sendai, 980-8574, Japan. Tel: +81 227177201, Fax: +81 227177209, e-mail: m_unno@surg.med.tohoku.ac.jp

Key Words: Pancreatic cancer, green fluorescent protein, gemcitabine, metastasis, opposite effect. $m g / k g$ for 6 weeks). Each group comprised eight mice. Tumor size, fluorescent area of metastases, and body weight were measured. Results: Low- and high-dose gemcitabine inhibited primary tumor growth in a dose-dependent manner, and to the greatest extent by high-dose gemcitabine compared to the untreated control $(p=0.0134)$. In contrast, the extent of metastasis on the peritoneum was significantly increased by low-dose gemcitabine compared to the untreated control $(p=0.0112)$. The extent of metastasis showed no significant difference between the untreated control and mice treated with high-dose gemcitabine. Body weight of the treated mice was not significantly different from that of the untreated mice. Conclusion: The use of very bright GFP expressing of BxPC-3 cells and the orthotopic model demonstrated an unexpected increase in metastasis by low-dose gemcitabine. Future experiments will investigate the mechanism of this phenomenon.

Pancreatic cancer accounts for approximately $3 \%$ of all cancer in the United States and about $7 \%$ of all cancer deaths (1). The 5-year survival rate of patients diagnosed with pancreatic cancer is still only $9 \%$, despite improvements in the past decade. Gemcitabine has been standard first-line treatment for patients with advanced pancreatic cancer since 1997 (2). Although many clinical trials tested new chemotherapy drugs combined with gemcitabine for pancreatic cancer, only combination therapy with nab-paclitaxel has been shown to be superior to gemcitabine alone (3).

The efficacy of chemotherapy against pancreatic cancer is limited in most cases due to drug resistance. Chemotherapy itself may induce some changes in the tumor microenvironment which can promote cancer cell proliferation and metastasis (4). We previously showed that the chemotherapeutic cyclophosphamide actually enhanced the malignancy of implanted 
cancer cells (5). Cyclophosphamide pretreatment enhanced intravascular proliferation, extravasation, and subsequent colony formation of HT1080 human fibrosarcoma cells. However, little is still known about the impact of the tumor microenvironment on chemotherapeutic outcome (6).

We have improved the utility of mouse models by transforming cancer cells with the green fluorescent protein (GFP) gene, from the jellyfish Aequorea victoria, to enable better detection of primary tumor growth and metastasis (7, 8). We also established an orthotopic model of metastatic pancreatic cancer where primary and metastatic sites can be imaged using GFP fluorescence (9). In particular, micrometastases are easy to detect by GFP fluorescence.

In the preset study, we evaluated efficacy of gemcitabine on primary tumor and growth of metastases in the BxPC-3expressing GFP orthotopic xenograft mouse model of pancreatic cancer. The aim of the present study was to identify whether gemcitabine can stimulate metastasis.

\section{Materials and Methods}

Mice. Athymic nu/nu nude mice (AntiCancer, Inc., San Diego, CA, USA), 4-6 weeks old, were used in this experiment. Animal housing and their diet were as previously described (10). Mice were observed on a daily basis and humanely sacrificed by $\mathrm{CO}_{2}$ inhalation with humane-endpoint criteria described in previous publications $(10,11)$. All mice were handled according to the principles and procedures outlined in the National Institutes of Health Guide for the Care and Use of Animals under Assurance Number A3873-1.

BxPC-3 human pancreatic cancer cells expressing green fluorescent protein (BxPC-3-GFP). The BxPC-3 human pancreatic cancer cell line was obtained from the American Type Culture Collection (Rockville, MD, USA). The cells were maintained in RPMI 1640 supplemented with $10 \%$ fetal bovine serum, and $1 \%$ penicillinstreptomycin at $37^{\circ} \mathrm{C}$ in $5 \% \mathrm{CO}_{2}$. GFP retroviral transduction and selection of high GFP-expressing BxPC-3 cells were established in our laboratory and previously reported $(9,11)$.

Surgical orthotopic implantation. BxPC-3-GFP cells $\left(2 \times 10^{6}\right.$ cells, $0.2 \mathrm{ml}$ ) in fetal bovine serum-free RPMI 1640 were subcutaneously injected into the shoulder of nude mice. Growing tumors were harvested and cut into $5 \mathrm{~mm}^{3}$ fragments for surgical orthotopic implantation. A $10 \mathrm{~mm}$ transverse incision was made on the left flank of the mouse under anesthesia. The pancreatic tail was exposed, and a single tumor fragment was implanted orthotopically into the pancreatic tail with 8-0 nylon suture (Ethicon, Inc., Somerville, NJ, USA). The wound was closed with 6-0 nylon suture (Ethicon, Inc.) $(10,12)$.

Treatment of the BxPC-3-GFP orthotopic xenograft model. The BxPC-3-GFP orthotopic xenograft mice were randomized into three groups of eight mice each when the tumor volume reached $60 \mathrm{~mm}^{3}$ and treated for 6 weeks as follows (Figure 1A): Group 1: untreated control; Group 2: low-dose gemcitabine (weekly intraperitoneal (i.p.) injection at $25 \mathrm{mg} / \mathrm{kg}$ ); Group 3: high-dose gemcitabine (weekly i.p. injection at $125 \mathrm{mg} / \mathrm{kg}$ ). Mouse body weight was measured twice a week. Tumor length and width were measured with calipers after opening the abdomen on day 0 and 42 . Tumor volume was calculated based on a previously published formula $(10,11)$.

Imaging of the fluorescent BxPC-3-GFP tumors and metastases. The abdomen was opened on day 42 for fluorescence imaging of the macroscopic tumor performed with the UVP ChemoStudio (Analytik Jena, Upland, CA, USA). The fluorescent area of the images was measured.

Histological examination. Fresh tumor samples from the mice were fixed, sectioned and stained as previously described $(10,11)$. Images were acquired with AmScope software (AmScope, Inc., Irvine, CA, USA).

Statistical analysis. The data are presented as the mean $\pm \mathrm{SD}$ and one-way ANOVA was performed to evaluate the differences between the means. A value of $p<0.05$ was considered to be statistically significant. Statistical analyses were conducted with GraphPad Prism 7 (GraphPad Software, Inc., San Diego, CA, USA).

\section{Results}

Effect of treatment on primary tumor growth. Primary tumor volume in the low-dose gemcitabine-treated group did not significantly differ from that of the untreated control $(p=0.2620)$. However, high-dose gemcitabine significantly inhibited primary tumor growth compared to the untreated control $(p=0.0134)$ (Figure 1B).

Effect of treatment on metastasis. No obvious metastasis with GFP was detected on day 0 when the treatment was started. Figure 2A shows representative fluorescence images after primary tumor resection from each group on day 42. GFPexpressing peritoneal metastases in mice treated with lowdose gemcitabine had a significantly increased area compared to that of the untreated control group $(p=0.0112)$. In contrast, there was no significant difference between the extent of GFP-expressing peritoneal metastasis in mice treated with high-dose gemcitabine and that of the untreated control $(p=0.7399)$ (Figure 2B).

Effect of treatment on body weight. Body weight did not significantly differ between each group pre-treatment and post-treatment (Figure 3A).

Effect of treatment on tumor histology. Figure 3B shows representative images of hematoxylin and eosin staining of the primary pancreatic tumors from each group resected on day 42. Extensive proliferation of viable cancer cells in the primary tumors was observed in the untreated control. Lowdose gemcitabine caused some necrosis and fibrosis among many viable cancer cells. Furthermore high-dose gemcitabine caused extensive necrosis and fibrosis in the primary tumor and few viable cancer cells were present. Figure 3B also 
A

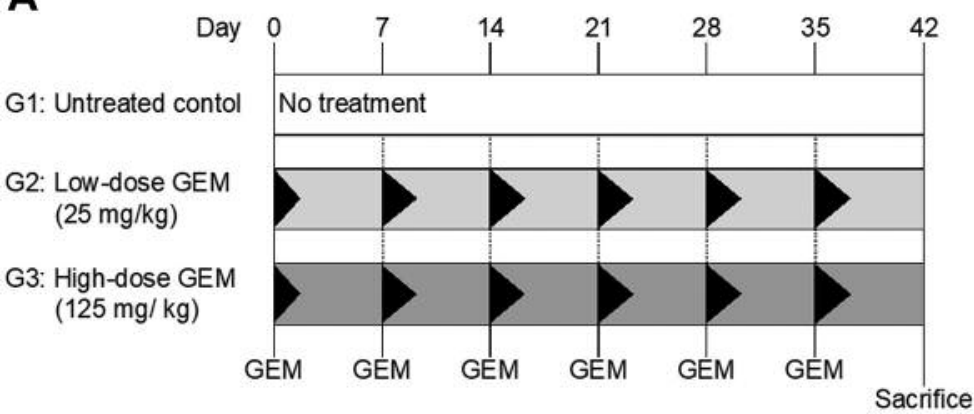

B

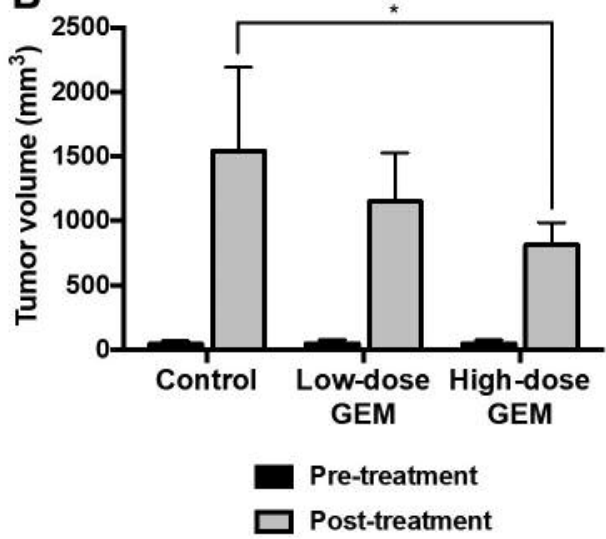

Figure 1. A: Treatment protocol for the BXPC-3 expressing green fluorescent protein (GFP) orthotopic xenograft mouse model. The mice were randomized into three groups of eight mice each: G1: untreated control, G2: low-dose gemcitabine (GEM), and G3: high-dose GEM. GEM was injected in the intraperitoneal cavity once a week for 6 weeks. B: Efficacy of GEM treatment on primary tumor volume in the pancreas. Bar graphs show the tumor volume at pre-treatment and post-treatment. Data are the mean $\pm S D$. $*$ Significantly different at $p<0.05$.

A

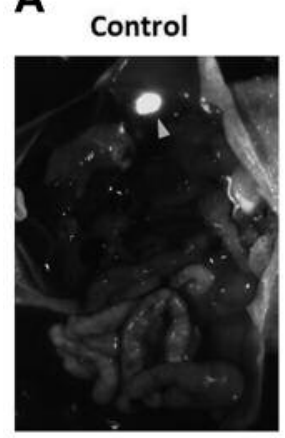

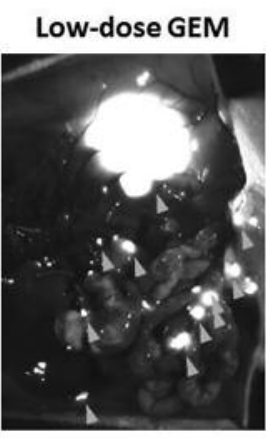

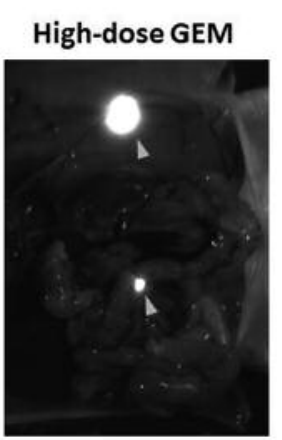

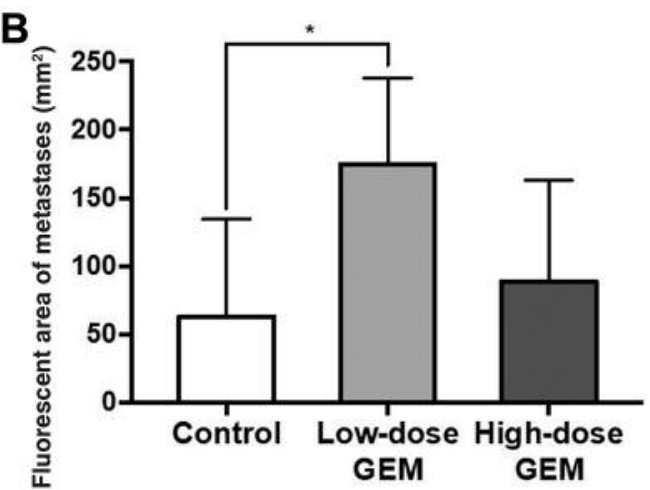

Figure 2. Effect of gemcitabine (GEM) treatment on metastasis. A: Fluorescence imaging of green fluorescent protein (GFP)-expressing metastases. The primary tumor was removed before imaging. High fluorescence intensity represents metastases with GFP (arrows). B: Quantitation of area of fluorescence of metastases with GFP. Data are the mean \pm SD. *Significantly different at $p<0.05$.

shows representative images of hematoxylin and eosin staining of the sites of peritoneal metastases resected from each group on day 42. Extensive proliferation of viable cancer cells in the peritoneal metastases was observed in all groups. There was no obvious difference in histology between these three groups at the metastatic sites.

\section{Discussion}

In the present study, high-dose (125 mg/kg, weekly) gemcitabine inhibited primary tumor growth in the BxPC3-GFP pancreatic cancer orthotopic xenograft mouse model. However, low-dose $(25 \mathrm{mg} / \mathrm{kg}$, weekly) gemcitabine had an opposite effect, increasing the extent of peritoneal metastases, without significant inhibition of primary tumor growth compared to the untreated control. In our previous study, weekly dosing with $100 \mathrm{mg} / \mathrm{kg}$ gemcitabine inhibited tumor growth in a PDOX mouse model of pancreatic cancer $(13,14)$. In another study, gemcitabine inhibited tumor growth in a pancreatic cancer xenograft mouse model in a dose-dependent manner (from 40 to $120 \mathrm{mg} / \mathrm{kg}$, weekly) (15). In the present study, weekly dosing of 125 $\mathrm{mg} / \mathrm{kg}$ gemcitabine was considered a high dose and weekly dosing of $25 \mathrm{mg} / \mathrm{kg}$ gemcitabine was considered low dose. In histological examination, gemcitabine caused necrosis and fibrosis in the primary tumor, which was developed more strongly using high-dose than with low-dose gemcitabine. 


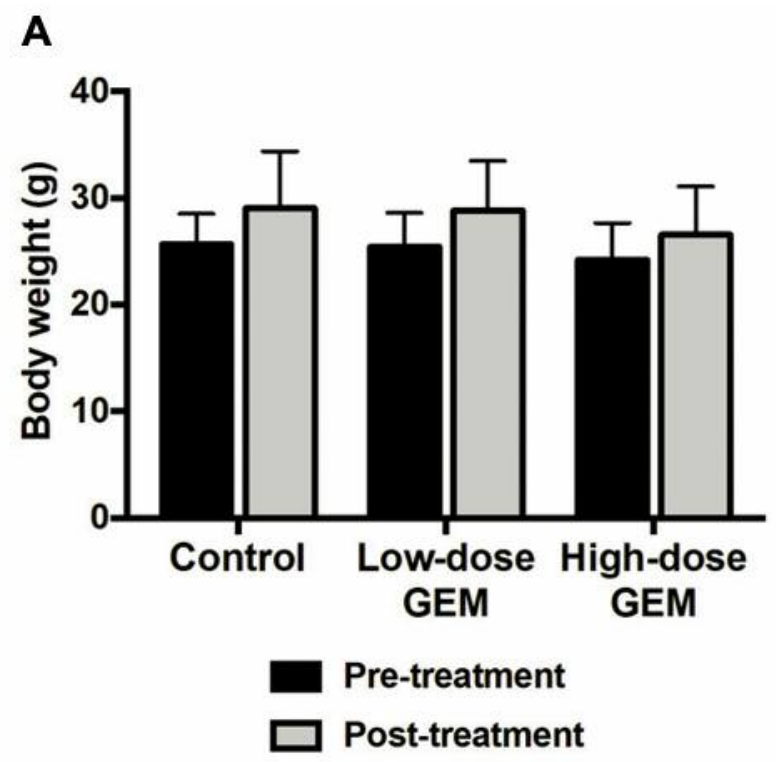

B

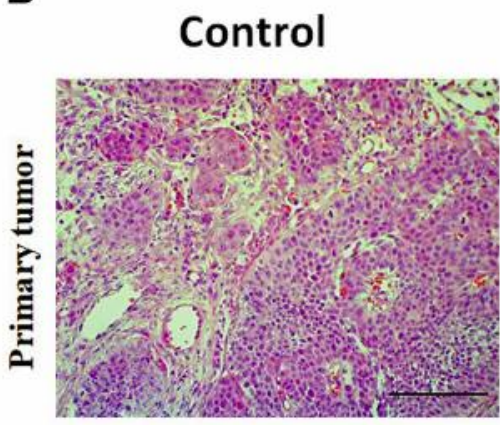

Low-dose GEM
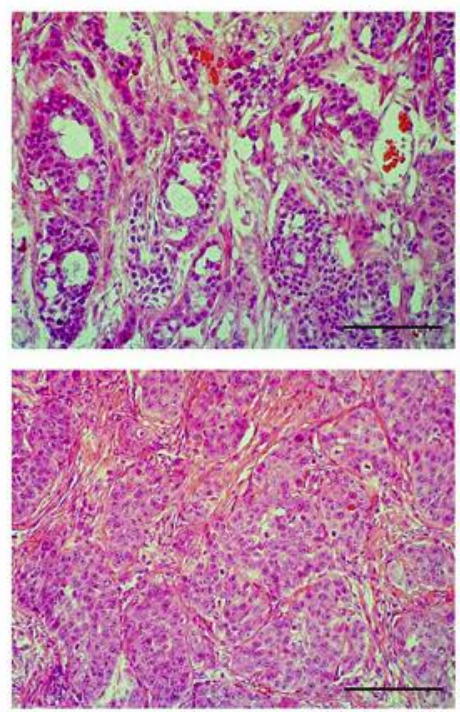

High-dose GEM
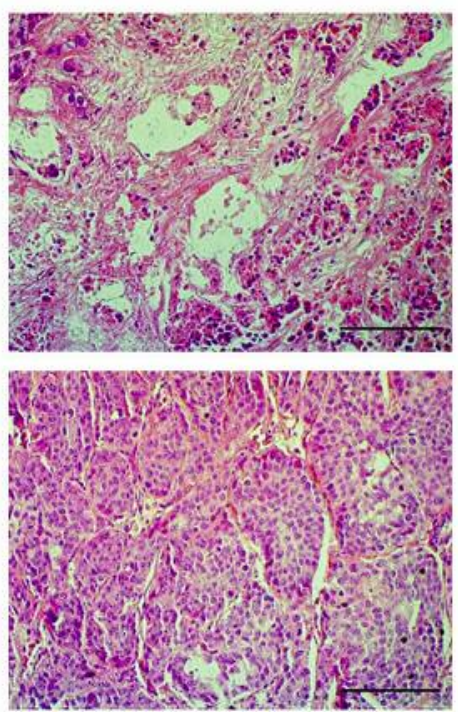

Figure 3. Body weight and tumor histology. A: Effect of gemcitabine (GEM) treatment on mouse body weight. Bar graphs show the tumor volume pre- and post-treatment. Data are the mean \pm SD B: Effect of GEM treatment on tumor histology, hematoxylin and eosin staining. Scale bars: 100 um.

The mechanisms underlying gemcitabine-induced metastasis remain unclear. Gemcitabine pharmacologically prevents the synthesis of deoxyribonucleotides required for DNA replication and repair (16). Gilbert et al. showed DNA damage creates a chemo-resistant niche that promotes the survival of cancer cells (6). According to the present histological findings, gemcitabine inhibited BxPC-3-GFP cells in the primary tumor but not on the peritoneum. It is possible that $\mathrm{BxPC}-3-\mathrm{GFP}$ cells that become metastatic also become relatively chemoresistant.
Cytotoxic chemotherapy drugs may change the tumor microenvironment (17), which might cause a negative effect of chemotherapy. In our previous studies, cyclophosphamide pretreatment enhanced intravascular proliferation, extravasation, and subsequent colony formation $(5,18)$. In other studies, cisplatin and paclitaxel induced expression of vascular endothelial growth factor receptor 1 on endothelial cells, creating an environment favorable for cancer cell homing (19), and paclitaxel was 
shown to promote liver metastasis of breast cancer cells in a mouse model (20). Furthermore, neoadjuvant chemotherapy of paclitaxel in a clinical trial may have induced expression breast cancer metastasis (21). D'Costa et al. reported that gemcitabine induced expression of tissue inhibitor of metalloproteinases 1 , which may promote tumor growth and liver metastasis in pancreatic cancer (22). Kerbel et al. investigated the relationship of drug resistance and metastasis $(23,24)$. They found that drug-resistant cancer cells clustered very tightly and that highly clustered cancer cells may possess an enhanced metastatic capability $(25,26)$. The p27 gene appears to regulate cancer-cell clustering. We will investigate this mechanism on GEMinduced metastasis in future studies. Our previous studies also implicated natural killer cells in preventing metastasis (27). It is possible that low-dose GEM may inhibit natural killer cells and induce metastasis. Kerbel et al. also showed that inhibiting angiogenesis increased metastasis by inducing hypoxia (28). We showed gemcitabine inhibited angiogenesis (29). Future studies will be needed to dissect the mechanism of gemcitabine-induced increase of metastasis.

In conclusion, the use of very bright GFP expression of BxPC-3 cells and the orthotopic model enabled us to observe an unexpected increase in metastasis induced by low-dose gemcitabine therapy. Future experiments will investigate the mechanism of this phenomenon and its implication for treating pancreatic cancer in the clinic with GEM (30).

\section{Conflicts of Interest}

The Authors declare that there are no potential conflicts of interest. AntiCancer, Inc. uses pancreatic cancer orthotopic xenograft mouse models for contract research. NS, KM, TH, HO, $\mathrm{ZZ}$, JP, and RMH are or were unsalaried associates of AntiCancer Inc.

\section{Funding}

This research did not receive any specific grant from funding agencies in the public, commercial, or not-for-profit sectors.

\section{Authors' Contributions}

Conception and design: NS and RMH. Acquisition of data: NS, $\mathrm{KM}, \mathrm{TH}, \mathrm{HO}$, JP, and KK. Analysis and interpretation of data: NS, KM, TH, HO, JP, KK, SPC, MB, SRS, MU, and RMH. Writing, review, and/or revision of the manuscript: NS, RMH, MU, and SRS.

\section{Acknowledgements}

This paper is dedicated to the memory of A. R. Moossa, M.D., Sun Lee, M.D., Professor Li Jiaxi, and Masaki Kitajima, M.D.

\section{References}

1 American Cancer Society: I. Survival Rates for Pancreatic Cancer, 2019. Available from: https://www.cancer.org/cancer/ pancreatic-cancer/detection-diagnosis-staging/survival-rates.html

2 Hammel P, Huguet F, van Laethem JL, Goldstein D, Glimelius B, Artru P, Borbath I, Bouché O, Shannon J, André T, Mineur L, Chibaudel B, Bonnetain F, Louvet C and LAP07 Trial Group: Effect of chemoradiotherapy $v s$. chemotherapy on survival in patients with locally advanced pancreatic cancer controlled after 4 months of gemcitabine with or without erlotinib: the LAP07 randomized clinical trial. JAMA 315(17): 1844-1853, 2016. PMID: 27139057. DOI: 10.1001/jama.2016.4324

3 Goldstein D, El-Maraghi RH, Hammel P, Heinemann V, Kunzmann V, Sastre J, Scheithauer W, Siena S, Tabernero J, Teixeira L, Tortora G, Van Laethem JL, Young R, Penenberg DN, Lu B, Romano A and Von Hoff DD: nab-Paclitaxel plus gemcitabine for metastatic pancreatic cancer: long-term survival from a phase III trial. J Natl Cancer Inst 107(2): dju413, 2015. PMID: 25638248. DOI: 10.1093/jnci/dju413

4 Martin OA, Anderson RL, Narayan K and MacManus MP: Does the mobilization of circulating tumour cells during cancer therapy cause metastasis? Nat Rev Clin Oncol 14(1): 32-44, 2017. PMID: 27550857. DOI: $10.1038 /$ nrclinonc.2016.128

5 Yamauchi K, Yang M, Hayashi K, Jiang P, Yamamoto N, Tsuchiya H, Tomita K, Moossa AR, Bouvet M and Hoffman RM: Induction of cancer metastasis by cyclophosphamide pretreatment of host mice: an opposite effect of chemotherapy. Cancer Res 68(2): 516-20, 2008. PMID: 18199547. DOI: 10.1158/0008-5472.CAN-07-3063

6 Gilbert LA and Hemann MT: DNA damage-mediated induction of a chemoresistant niche. Cell 143(3): 355-366, 2010. PMID: 21029859. DOI: 10.1016/j.cell.2010.09.043

7 Bouvet M, Yang M, Nardin S, Wang X, Jiang P, Baranov E, Moossa AR and Hoffman RM: Chronologically-specific metastatic targeting of human pancreatic tumors in orthotopic models. Clin Exp Metastasis 18(3): 213-218, 2000. PMID: 11315094. 10.1023/A:1006767405609

8 Hoffman RM: The multiple uses of fluorescent proteins to visualize cancer in vivo. Nat Rev Cancer 5(10): 796-806, 2005. PMID: 16195751. DOI: 10.1038/nrc1717

9 Bouvet M, Wang J, Nardin SR, Nassirpour R, Yang M, Baranov E, Jiang P, Moossa AR and Hoffman RM: Real-time optical imaging of primary tumor growth and multiple metastatic events in a pancreatic cancer orthotopic model. Cancer Res 62(5): 1534-1540, 2002. PMID: 11888932.

10 Kawaguchi K, Miyake K, Han Q, Li S, Tan Y, Igarashi K, Kiyuna T, Miyake M, Higuchi T, Oshiro H, Zhang Z, Razmjooei $S$, Wangsiricharoen S, Bouvet M, Singh SR, Unno M and Hoffman RM: Oral recombinant methioninase (o-rMETase) is superior to injectable rMETase and overcomes acquired gemcitabine resistance in pancreatic cancer. Cancer Lett 432: 251-259, 2018. PMID: 29928962. DOI: 10.1016/j.canlet.2018. 06.016

11 Hoffman RM and Yang M: Whole-body imaging with fluorescent proteins. Nat Protoc 1(3): 1429-1438, 2006. PMID: 17406431. DOI: $10.1038 /$ nprot.2006.223

$12 \mathrm{Fu}$ X, Guadagni F and Hoffman RM: A metastatic nude-mouse model of human pancreatic cancer constructed orthotopically with histologically intact patient specimens. Proc Natl Acad Sci 
USA 89(12): 5645-5649, 1992. PMID: 1608975. DOI: 10.1073/ pnas.89.12.5645

13 Kawaguchi K, Igarashi K, Miyake K, Lwin TM, Miyake M, Kiyuna T, Hwang HK, Murakami T, Delong JC, Singh SR, Clary B, Bouvet M, Unno $M$ and Hoffman RM: MEK inhibitor trametinib in combination with gemcitabine regresses a patientderived orthotopic xenograft (PDOX) pancreatic cancer nude mouse model. Tissue Cell 52: 124-128, 2018. PMID: 29857821. DOI: $10.1016 /$ j.tice.2018.05.003

14 Kawaguchi K, Miyake K, Han Q, Li S, Tan Y, Igarashi K, Lwin TM, Higuchi T, Kiyuna T, Miyake M, Oshiro H, Bouvet M, Unno $\mathrm{M}$ and Hoffman RM: Targeting altered cancer methionine metabolism with recombinant methioninase (rMETase) overcomes partial gemcitabine-resistance and regresses a patientderived orthotopic xenograft (PDOX) nude mouse model of pancreatic cancer. Cell Cycle 17(7): 868-873, 2018. PMID: 29623758. DOI: 10.1080/15384101.2018.1445907

$15 \mathrm{Yu} \mathrm{H}$, Song H, Xiao J, Chen H, Jin X, Lin X, Pan B and Ji W: The effects of novel chitosan-targeted gemcitabine nanomedicine mediating cisplatin on epithelial mesenchymal transition, invasion and metastasis of pancreatic cancer cells. Biomed Pharmacother 96: 650-658, 2017. PMID: 29035831. DOI: 10.1016/j.biopha.2017.10.026

16 Mini E, Nobili S, Caciagli B, Landini I and Mazzei T: Cellular pharmacology of gemcitabine. Ann Oncol 17(Suppl 5): v7-12, 2006. PMID: 16807468. DOI: 10.1093/annonc/mdj941

17 Karagiannis GS, Condeelis JS and Oktay MH: Chemotherapyinduced metastasis: mechanisms and translational opportunities. Clin Exp Metastasis 35(4): 269-284, 2018. PMID: 29307118. DOI: $10.1007 / \mathrm{s} 10585-017-9870-\mathrm{x}$

18 Tsuji K, Yamauchi K, Yang M, Jiang P, Bouvet M, Endo H, Kanai Y, Yamashita K, Moossa AR and Hoffman RM: Dualcolor imaging of nuclear-cytoplasmic dynamics, viability, and proliferation of cancer cells in the portal vein area. Cancer Res, 2006. 66(1): 303-306, 2006. PMID: 16397243. DOI: 10.1158/ 0008-5472.CAN-05-2958

19 Daenen LG, Roodhart JM, van Amersfoort M, Dehnad M, Roessingh W, Ulfman LH, Derksen PW, and Voest EE: Chemotherapy enhances metastasis formation via VEGFR-1expressing endothelial cells. Cancer Res 71(22): 6976-6985, 2011. PMID: 21975929. DOI: 10.1158/0008-5472.CAN-11-0627

20 Li Q, Ma Z, Liu Y, Kan X, Wang C, Su B, Li Y, Zhang Y, Wang P, Luo Y, Na D, Wang L, Zhang G, Zhu X and Wang L: Low doses of paclitaxel enhance liver metastasis of breast cancer cells in the mouse model. FEBS J 283(15): 2836-2852, 2016. PMID: 27307301. DOI: $10.1111 /$ febs. 13767

21 Karagiannis GS, Pastoriza JM, Wang Y, Harney AS, Entenberg D, Pignatelli J, Sharma VP, Xue EA, Cheng E, D'Alfonso TM, Jones JG, Anampa J, Rohan TE, Sparano JA, Condeelis JS and Oktay MH: Neoadjuvant chemotherapy induces breast cancer metastasis through a TMEM-mediated mechanism. Sci Transl Med 9(397): eaan0026, 2017. PMID: 28679654. DOI: 10.1126/ scitranslmed.aan0026
22 D'Costa Z, Jones K, Azad A, van Stiphout R, Lim SY, Gomes AL, Kinchesh P, Smart SC, Gillies McKenna W, Buffa FM, Sansom OJ, Muschel RJ, O’Neill E and Fokas E: Gemcitabineinduced TIMP1 attenuates therapy response and promotes tumor growth and liver metastasis in pancreatic cancer. Cancer Res 77(21): 5952-5962, 2017. PMID: 28765154. DOI: 10.1158/ 0008-5472.CAN-16-2833

23 Kerbel RS, Rak J, Kobayashi H, Man MS, St Croix B and Graham CH: Multicellular resistance: a new paradigm to explain aspects of acquired drug resistance of solid tumors. Cold Spring Harb Symp Quant Biol 59: 661-672, 1994. PMID: 7587127. DOI: $10.1101 / \mathrm{sqb} .1994 .059 .01 .076$

24 Kobayashi H, Man S, Graham CH, Kapitain SJ, Teicher BA and Kerbel RS: Acquired multicellular-mediated resistance to alkylating agents in cancer. Proc Natl Acad Sci USA 90(8): 32943298, 1993. PMID: 8475071. DOI: 10.1073/pnas.90. 8.3294

25 St Croix B, Flørenes VA, Rak JW, Flanagan M, Bhattacharya N, Slingerland JM and Kerbel RS: Impact of the cyclin-dependent kinase inhibitor p27KIP1 on resistance of tumor cells to anticancer agents. Nat Med 2(11): 1204-1210, 1996. PMID: 8898746.

26 Croix BS, Rak JW, Kapitain S, Sheehan C, Graham CH and Kerbel RS: Reversal by hyaluronidase of adhesion-dependent multicellular drug resistance in mammary carcinoma cells. J Natl Cancer Inst 88(18): 1285-1296, 1996. PMID: 8797768. DOI: $10.1093 /$ jnci/88.18.1285

27 Furukawa T, Kubota T, Watanabe M, Kuo TH, Kitajima M and Hoffman RM: Differential chemosensitivity of local and metastatic human gastric cancer after orthotopic transplantation of histologically intact tumor tissue in nude mice. Int $\mathrm{J}$ Cancer 54(3): 397-401, 1993. PMID: 8509214. DOI: 10.1002/ijc.291 0540308

28 Ebos JM, Lee CR, Cruz-Munoz W, Bjarnason GA, Christensen JG and Kerbel RS: Accelerated metastasis after short-term treatment with a potent inhibitor of tumor angiogenesis. Cancer Cell 15(3): 232-239, 2009. PMID: 19249681. DOI: 10.1016/ j.ccr.2009.01.021

29 Amoh Y, Nagakura C, Maitra A, Moossa AR, Katsuoka K, Hoffman $\mathrm{RM}$, Bouvet M: Dual-color imaging of nascent angiogenesis and its inhibition in liver metastases of pancreatic cancer. Anticancer Res 26(5A): 3237-3242, 2006. PMID: 17094435.

30 Kuo TH, Kubota T, Watanabe M, Furukawa T, Teramoto T, Ishibiki K, Kitajima M, Moossa AR, Penman S and Hoffman RM: Liver colonization competence governs colon cancer metastasis. Proc Natl Acad Sci USA 92(26): 12085-12089, 1995. PMID: 8618849. DOI: 10.1073/pnas.92.26.12085
Received August 20, 2019

Revised September 11, 2019

Accepted September 13, 2019 